\title{
The K1 Capsule Is the Critical Determinant in the Development of Escherichia coli Meningitis in the Rat
}

Kwang Sik Kim, * Hideo Itabashi, ” Peter Gemski," Jerald Sadoff," Richard L. Warren," and Alan S. Cross"

* Department of Pediatrics, Children's Hospital of Los Angeles, University of Southern California School of Medicine, Los Angeles, California 90027; ${ }^{\ddagger}$ Department of Pathology, Harbor-UCLA Medical Center, UCLA School of Medicine, Torrance, California 90509; and Departments of ${ }^{\S}$ Molecular Pathology and "Bacterial Diseases, Walter Reed Army Institute of Research,

Washington, District of Columbia 20307

\begin{abstract}
Although Escherichia coli strains possessing the $\mathrm{K} 1$ capsule are predominant among isolates from neonatal $E$. coli meningitis and most of these $\mathrm{K} 1$ isolates are associated with a limited number of 0 lipopolysaccharide (LPS) types, the basis of this association of $\mathrm{K} 1$ and certain 0 antigens with neonatal $E$. coli meningitis is not clear. The present study examined in experimental $E$. coli bacteremia and meningitis in newborn and adult rats whether or not the K1 capsule and/or 0-LPS antigen are critical determinants in the development of meningitis. Rats received subcutaneously a K1 $E$. coli strain $(018+K 1+)$ or mutants lacking either the $\mathrm{K} 1$ capsule $(018+K 1-)$ or 0 side-chain (018-K1+). 12-24 h later, blood and cerebrospinal fluid (CSF) specimens were obtained for quantitative cultures. The isolation of $E$. coli from CSF was observed in both newborn and adult rats infected with $\mathrm{K1}+$ strains regardless of LPS phenotype $(018+$ or $18-)$ who also developed a high degree of bacteremia (e.g., $>10^{4} \mathrm{CFU} / \mathrm{ml}$ of blood). In contrast, none of the newborn and adult rats infected with $018+\mathrm{K} 1-$ and developing bacteremia of $>10^{4}$ were found to have positive CSF cultures. These findings indicate that the presence of the K1 capsule and a high degree of bacteremia are key determinants in the development of $\boldsymbol{E}$. coli meningitis, suggesting that there may be specific binding sites present in the brain which have an affinity for the $\mathrm{K} 1$ capsule and thus may be responsible for the entry of K1-encapsulated $E$. coli into the meninges. (J. Clin. Invest. 1992. 90:897-905.) Key words: Escherichia coli $\bullet$ hematogenous meningitis - lipopolysaccharide - K1 capsular polysaccharide • pathogenesis
\end{abstract}

\section{Introduction}

The mortality and morbidity associated with neonatal gramnegative bacillary meningitis have remained significant despite advances in antimicrobial chemotherapy and supportive care $(1,2)$. Both clinical and experimental data indicate limited efficacy with antimicrobial chemotherapy alone $(3,4)$. A contributing factor may be the incomplete development of host defense mechanisms in neonates $(5,6)$. Thus, adjunct therapy

Address reprint requests to Dr. Kim, Box 51, Division of Infectious Diseases, Children's Hospital of Los Angeles, 4650 Sunset Boulevard, Los Angeles, CA 90027.

Received for publication 6 December 1989 and in revised form 10 March 1992.

J. Clin. Invest.

(c) The American Society for Clinical Investigation, Inc.

0021-9738/92/09/0896/09 \$2.00

Volume 90, September 1992, 897-905 in the form of active or passive immunotherapy is a logical next step. The feasibility of this approach, however, is limited by inadequate understanding of host-microbial factors associated with the increased susceptibility of neonates to gram-negative bacilli.

Escherichia coli is the most common gram-negative organism that causes meningitis during the neonatal period $(1,2)$. Given the plethora of $E$. coli serotypes (e.g., 103 capsular or K, 1700 lipopolysaccharides or LPS, and 56 flagellar or $\mathrm{H}$ antigens) (7), it is striking that $E$. coli strains possessing the $\mathrm{K} 1$ capsular polysaccharide are predominant $(\sim 80 \%)$ among isolates from neonatal $E$. coli meningitis (8-10). It is also of interest that only a few somatic antigens (e.g., 018, 07, 01, 016) have been associated with most of the $\mathrm{K} 1$ strains isolated from the cerebrospinal $(\mathrm{CSF})^{1}(11)$. The basis of this association of $\mathrm{K} 1$ and certain 0 antigens with neonatal $E$. coli meningitis is not clear.

We have previously shown that experimental $E$. coli bacteremia and meningitis in newborn rats have important similarities to human newborn $E$. coli infection. Hematogenous infection of meninges can be reliably established without the need for administration of adjuvant or direct inoculation of bacteria into CSF $(4,12-17)$. With development of techniques for atraumatic collection of blood and CSF specimens, we have used this model to determine whether or not the $\mathrm{K} 1$ capsule and/or 0-LPS antigen are critical determinants in the development of $E$. coli meningitis.

\section{Methods}

Bacterial strains. A serum-resistant $E$. coli strain possessing the $\mathrm{K} 1$ capsular polysaccharide, C5 (serotype $018: \mathrm{K} 1: \mathrm{H} 7$ ) was originally obtained from Dr. R. Bortolussi, Dalhousie University, Halifax, Nova Scotia, Canada. This strain was isolated from the CSF of a newborn infant with meningitis (12). The presence of the $\mathrm{K} 1$ capsule was confirmed by lytic sensitivity to the K1-specific bacteriophages (18-20) as well as by the antiserum agar technique with equine antiserum to group B meningococcus (11). Salmonella typhimurium strain X3604 cya::Tn 10 was obtained from Dr. R. Curtiss III, Department of Biology, Washington University, St. Louis, MO.

K1-negative derivatives. Unencapsulated mutants of strain C5 were obtained by selection for resistance to the $\mathrm{K} 1$-specific bacteriophages (phages A, B, C, D, E) as previously described (18-20). Each clone was then reexamined for the loss of capsule production using the K1-specific bacteriophages as well as the antiserum agar technique. Previous studies in our laboratories have shown no detectable differences in LPS and outer membrane protein complex between parents and $\mathrm{K} 1-$ clones when examined by SDS-PAGE (20-22). Parent K1+ strains and their $\mathrm{K} 1-$ mutants also possess identical hemolysin, biochemical

1. Abbreviations used in this paper: $\mathrm{CSF}$, cerebrospinal fluid; $\mathrm{Tc}^{\mathrm{R}}$, tetracycline resistance (gene). 
reactions, and binding patterns to homologous LPS monoclonal antibody (by Western blot using whole organisms or LPS). In addition, parent $\mathrm{K} 1+$ strain and $\mathrm{K} 1-$ mutants were found to have identical genotypes when examined by the multilocus enzyme electrophoresis (kindly performed by Dr. Richard Wilson at $E$. coli Reference Center, Pennsylvania State University, State College, PA). K1 - mutants were stable and reversion to their $\mathrm{K} 1+$ status has not been observed either after $>10$ years of storage at $-70^{\circ} \mathrm{C}$ or after $>10$ passages in vitro and in vivo rats.

Rough mutants. Two different rough mutants of strain C5 were generated. The first type of rough mutant was obtained by treatment with $N$-methyl- $N$-nitro- $N$-nitrosoguanidine as described previously (19). Briefly, strain C5 grown overnight in $10 \mathrm{ml}$ of fresh broth was centrifuged and resuspended in $0.5 \mathrm{ml}$ of fresh broth. $0.1 \mathrm{ml}$ of $N$ methyl- $N$-nitro- $N$-nitrosoguanindine $(4.0 \mu \mathrm{g} / \mathrm{ml})$ was then added. After $20 \mathrm{~min}$ of incubation at $37^{\circ} \mathrm{C}, 4.5 \mathrm{ml}$ of additional broth was added and incubation was continued for another $5 \mathrm{hs}$, at which time the bacterial suspension was diluted and plated on agar. Most isolates that survived this treatment were found to retain the $\mathrm{K} 1+$ phenotype. Potential mutants that produced rough colony appearance were selected and confirmed as producing rough LPS by SDS-PAGE and sensitivity to rough-specific bacteriophages $(19,20,22)$. These rough mutants were also found to have different outer membrane protein complex compared to the parent strain C5 (22).

The second type of rough mutants was prepared by mutagenesis with transposon Tn $10(23,24)$. E. coli auxotrophic donor C600, carrying the temperature-sensitive $F_{\text {ts }}^{\prime} 114$ lac plasmid into which the tetracycline ( $\mathrm{Tc}$ )-resistant transposon $\mathrm{Tn} 10$ had been inserted, was mated with strain $\mathrm{C} 5$ at $32^{\circ} \mathrm{C}$. Selection for transconjugants that inherited $F_{t s}^{\prime} 114$ lac::Tn 10 was achieved by plating mating mixtures on minimal salts glucose agar supplemented with Tc $(20 \mu \mathrm{g} / \mathrm{ml})$. After incubation at $32^{\circ} \mathrm{C}$ for $48 \mathrm{~h}$, several $\mathrm{Tc}^{\mathrm{R}}$ strain $\mathrm{C} 5$ transconjugants were isolated. One of these strain $\mathrm{C} 5$ derivatives harboring the $\mathrm{F}_{\text {ts }}^{\prime} 114$ lac::Tn 10 plasmid was chosen for transposition mutagenesis. To select for transposition of $\mathrm{Tn} 10$, this transconjugant was serially cultured at a restrictive temperature $\left(42^{\circ} \mathrm{C}\right)$ and plated on Trypticase soy Agar (BBL Microbiology Systems, Cockeyville, MD) containing Tc (20 $\mu \mathrm{g} /$ $\mathrm{ml}$ ). After incubation at $37^{\circ} \mathrm{C}$ overnight, $\mathrm{Tc}^{\mathrm{R}}$ derivatives were examined for rough colonial morphology via a binocular microscope. Tentative rough mutants were picked and scored for their LPS phenotype via spot tests for sensitivity to rough specific bacteriophages. Unlike smooth strain $\mathrm{C} 5$ which is resistant to these phages, rough mutants were sensitive to phages BR2, Ffm, and BR60 (18-20).

Two rough mutants (strain XYL derived from nitrosoguanidine mutagenesis and strain 2513 derived from transposon mutagenesis) chosen for animal studies were found to differ from the parent strain only at one locus when examined by the multilocus enzyme electrophoresis, which in each case was a null allele, reflecting a lack of enzyme activity at the loci (suggestive of isogenicity according to Dr. Richard Wilson, Pennsylvania State University).

Southern blot analysis of Tn 10 derived mutants. EcoR1- and HindIII-digested $E$. coli DNA was separated by electrophoresis through a $1.0 \%$ agarose gel in TBE buffer $(0.05 \mathrm{M}$ Tris base $/ 0.05 \mathrm{M}$ boric acid/0.001 M EDTA, pH 8.3). DNA was transferred to neutral nylon membrane by capillary action with $10 \times \operatorname{SSC}(1.5 \mathrm{M} \mathrm{NaCl} / 0.15 \mathrm{M} \mathrm{Na}$ citrate), and then fixed to the nylon membrane by exposure to 12,000 $\mathrm{J} / \mathrm{cm}^{2} \mathrm{UV}$. The filter was prehybridized with hybridization buffer $(6 \times$ SSC, $5 \times$ Denhardt's solution, $10 \%$ dextran sulfate, $1 \%$ SDS, and $100 \mu \mathrm{g}$ denatured Salmon sperm DNA) at $65^{\circ} \mathrm{C}$ for $1 \mathrm{~h}$. The filter was probed with random primer labeled tetracycline resistance $\left(\mathrm{Tc}^{\mathrm{R}}\right)$ gene DNA at $65^{\circ} \mathrm{C}$, with $2 \times$ SSC, $0.5 \%$ SDS, $1 \times$ SSC, $1 \%$ SDS and then $0.1 \times$ SSC, $1 \%$ SDS. X-ray film was exposed overnight at $-70^{\circ} \mathrm{C}$ with the nylon membrane.

The $\mathrm{Tc}^{\mathrm{R}}$ gene $\mathrm{DNa}$ was isolated by polymerase chain reaction from $S$ typhimurium cya::Tn 10. Five microliters of a log-phase bacterial suspension was diluted into $45 \mu \mathrm{l}$ of distilled $\mathrm{H}_{2} \mathrm{O}$, boiled for $4 \mathrm{~min}$, and then rapidly cooled on ice. To $0.5 \mu$ l of target DNA $\mathrm{Tc}^{\mathrm{R}}$ gene primers (100 pM 5'-GCTCTAATGCGCTGT-3'，5'-GATCCAAGAGAAC-
CAAC-3'), $200 \mu \mathrm{M}$ dATP, $200 \mu \mathrm{M}$ dGTP, $200 \mu \mathrm{M}$ dTTP, and $100 \mu \mathrm{M}$ $\mathrm{dCTP}$, and $1 \mathrm{U}$ of AmpliTaq polymerase (Perkin-Elmer Cetus Corp., Emeryville, CA ) were mixed in reaction buffer ( $25 \mathrm{mM}$ Taps $\mathrm{HCl}, \mathrm{pH}$ 9.3/50 mM KCl/2 mM MgCl$/ 1$ mM 2-mercaptoethanol). The $\mathrm{Tc}^{\mathrm{R}}$ gene primers flank bp 1478-3098 of Tn 10 (23). This- $1620 \mathrm{bp}$ amplified contains a single EcoR 1 site 2,204 bp, and a single HindIII site $3,072 \mathrm{bp}$. The reaction mix was heated to $94^{\circ} \mathrm{C}$ in a DNA thermal cycler (Perkin-Elmer Cetus Corp.) for $5 \mathrm{~min}$, then five cycles of reannealing at $40^{\circ} \mathrm{C}$ for $3 \mathrm{~min}$, DNA synthesis at $72^{\circ} \mathrm{C}$ for $1 \mathrm{~min}$, and denaturation at $94^{\circ} \mathrm{C}$ for $1 \mathrm{~min}$. This was followed by 25 cycles of reannealing at $60^{\circ} \mathrm{C}$ for $2 \mathrm{~min}$, DNA synthesis at $72^{\circ} \mathrm{C}$ for $1 \mathrm{~min}$ and denaturation at $94^{\circ} \mathrm{C}$ for $1 \mathrm{~min}$. After DNA amplification, a single 2,600-bp product was detected by agarose gel electrophoresis.

Animal model for E. coli infection. E. coli bacteremia and meningitis were induced in 5-d-old rats by a previously described method (4). Briefly, outbred, pathogen-free, pregnant Sprague-Dawley rats with timed conception were purchased from Charles River Breeding Laboratories (Wilmington, MA); the rats delivered in our vivarium 5-7 d after arrival. Each adult rat and her pups (average litter size of 10 with range of 8-16) were housed in a solid-polypropylene opaque cage under a Small Animal Isolator (model 1894, Forma Scientific, Inc., Marietta, $\mathrm{OH}$ ).

At $5 \mathrm{~d}$ of age, all members of each litter were randomly divided into three groups to receive subcutaneously $4-10 \times \mathrm{LD}_{50}$ of each $E$. coli strain. $\mathrm{LD}_{50}$ 's in 5-d-old-rats were $30 \mathrm{CFU}$ for strain $\mathrm{C} 5,2.8 \times 10^{6} \mathrm{CFU}$ for the unencapsulated mutant and $5.0 \times 10^{6}$ to $1.0 \times 10^{7} \mathrm{CFU}$ for the rough mutants (strains XYL and 2513). $24 \mathrm{~h}$ after inoculation, blood and CSF specimens were obtained as described previously $(4,12-17)$ for quantitative cultures. In blood and CSF specimens obtained from animals infected with strain 2513 , agar containing Tc $(20 \mu \mathrm{g} / \mathrm{ml})$ was used for cultures. Immediately after obtaining blood and CSF specimens, the brains of selected animals were fixed in $10 \%$ formaldehyde and examined for the evidence of leptomeningitis. Bacteria were identified using Brown and Brenn stain.

We also examined whether or not the K1 capsule and 0-LPS were the key factors in the development of $E$. coli meningitis in adult rats (weighing $\sim 300 \mathrm{~g}$ ). Briefly, pathogen-free Sprague-Dawley adult rats received intravenously $4 \times \mathrm{LD}_{50}$ of each $E$. coli strain. $\mathrm{LD}_{50}$ 's in adult rats were $5.2 \times 10^{8} \mathrm{CFU}$ for strain $\mathrm{C} 5,3.7 \times 10^{9} \mathrm{CFU}$ for the unencapsulated mutant and $5.1 \times 10^{9}$ to $1.0 \times 10^{10} \mathrm{CFU}$ for the rough mutants (strains XYL and 2513). 12-24 h after inoculation, blood and CSF specimens were obtained for quantitative cultures.

To confirm that all isolates derived from animals maintained their status of unencapsulation and rough LPS, one colony each of blood and CSF isolates from each animal were retested for the K1 capsule with the K1-specific phages and the antiserum agar technique and for rough LPS with the rough specific bacteriophages.

\section{Results}

Studies in infant rats. Table I summarizes the prevalence of meningitis (defined as positive CSF cultures) in 5-d-old rats with varying degrees of bacteremia caused by strain $\mathrm{C} 5$ or its derivatives lacking the $\mathrm{K} 1$ capsule $(018+\mathrm{K} 1-)$ or 0 -LPS $(018-K 1+)$. Bacterial counts in blood $24 \mathrm{~h}$ after subcutaneous inoculation varied widely, ranging from $1 \times 10^{3} \mathrm{CFU} / \mathrm{ml}$ to 2 $\times 10^{9} \mathrm{CFU} / \mathrm{ml}$ of blood. At this time, some animals were also found to have positive CSF cultures and bacterial counts in CSF varied from $<5 \times 10^{3}$ (lower limit of detection) to 2 $\times 10^{9} \mathrm{CFU} / \mathrm{ml}$ of CSF. E. coli isolates from the blood and CSF of animals infected with $018+\mathrm{K} 1-$ or $018-\mathrm{K} 1+$ were tested for their $\mathrm{K1}-$ or $018-$ status. All isolates maintained their status of unencapsulation or rough LPS, respectively, and reversion to the status of their parent strain $(018+\mathrm{K} 1+)$ did not occur in vivo. 
Table I. Development of Meningitis (Defined as Positive CSF Culture) in Newborn Rats with Varying Degrees of Bacteremia

\begin{tabular}{ccccc}
\hline & \multicolumn{4}{c}{$\begin{array}{c}\text { Number of animals with positive CSF culture/number } \\
\text { of animals with positive blood culture }\end{array}$} \\
\cline { 2 - 5 } $\begin{array}{c}\text { Bacteremia } \\
\text { CFU/ml of } \\
\text { blood }\end{array}$ & $\begin{array}{c}\text { Strain C5* } \\
(018+\mathrm{K} 1+)\end{array}$ & $\begin{array}{c}\text { C5 mutant* } \\
(018+\mathrm{K} 1-)\end{array}$ & $\begin{array}{c}\text { Strain XYL* } \\
(018-\mathrm{K} 1+)\end{array}$ & $\begin{array}{c}\text { Strain } 2513^{*} \\
(018-\mathrm{K} 1+:: \mathrm{Tn} 10)\end{array}$ \\
\hline$<10^{4}$ & $0 / 9$ & $0 / 8$ & $0 / 11$ & $0 / 5$ \\
$10^{4}$ to $<10^{5}$ & $2 / 20(10 \%)$ & $0 / 22$ & $0 / 8$ & $1 / 7(14 \%)$ \\
$10^{5}$ to $<10^{6}$ & $10 / 25(40 \%)$ & $0 / 19$ & $5 / 16(31 \%)$ & $3 / 15(20 \%)$ \\
$10^{6}$ to $<10^{7}$ & $4 / 10(40 \%)$ & $0 / 10$ & $7 / 15(46 \%)$ & $5 / 18(28 \%)$ \\
$>10^{7}$ & $19 / 23(83 \%)$ & $0 / 9$ & $5 / 6(83 \%)$ & $8 / 13(62 \%)$
\end{tabular}

* See Methods for description of strains.

The isolation of $E$. coli from CSF was observed in animals infected with $\mathrm{K} 1+$ strains and also developing a high degree of bacteremia (e.g., $>10^{4} \mathrm{CFU} / \mathrm{ml}$ of blood). Overall $35 / 78$ $(45 \%)$ of animals infected with strain C5 $(018+\mathrm{K} 1+), 17 / 45$ $(38 \%)$ of animals infected with strain XYL $(018-\mathrm{K} 1+)$ and $17 / 53(32 \%)$ of animals infected with strain 2513 $(018-\mathrm{K} 1+:: \mathrm{Tn} 10)$ and also developing bacteremia of $>10^{4}$ $\mathrm{CFU} / \mathrm{ml}$ of blood were found to have positive CSF cultures. For the unencapsulated mutant $(018+\mathrm{K} 1-), 60$ animals developed a similar level of bacteremia (i.e., $>10^{4} \mathrm{CFU} / \mathrm{ml}$ of blood ); however, none had positive CSF cultures $(P<0.001$ compared to $018+\mathrm{K} 1+$ or $018-\mathrm{K} 1+$ strain ).

We next examined the brains of selective animals with positive CSF cultures. Fig. 1 was derived from a 5-d-old rat infected with strain $\mathrm{C} 5(018+\mathrm{K} 1+)$, which was found to have bacterial counts of $4 \times 10^{7} \mathrm{CFU} / \mathrm{ml}$ of CSF, and Fig. 2 from an animal infected with strain $2513(018-\mathrm{K} 1+:: \mathrm{Tn} 10)$ and possessing CSF bacterial counts of $5 \times 10^{7} \mathrm{CFU} / \mathrm{ml}$. As shown, the histopathological examinations of the brains of such rats with positive CSF cultures revealed the presence of gram-negative rods in the subarachnoid space predominantly around the perivascular areas (Figs. 1 and 2), but not in the chroid plexus (Fig. 3). Of interest, a concomitant response of inflammatory cells (e.g., $\mathrm{PMN}$, macrophages) was lacking at this stage of $E$. coli meningitis (Figs. 1 and 2).

Studies in adult rats. Fig. 4 illustrates the development meningitis (defined as positive CSF cultures) in adult animals with varying degrees of bacteremia caused by different $E$. coli strains. The isolation of $E$. coli from CSF was again observed in animals developing a high degree of bacteremia caused by $\mathrm{K} 1+$ strains regardless of LPS phenotype; $3 / 5(60 \%)$ of adult rats infected with strain $\mathrm{C} 5(018+\mathrm{K} 1+)$ and $5 / 10(50 \%)$ of adult animals infected with strain XYL $(018-\mathrm{K} 1+)$ and also developing bacteremia $>10^{4} \mathrm{CFU} / \mathrm{ml}$ of blood were found to have positive CSF cultures. In contrast, none of the 10 animals infected with $018+\mathrm{K} 1-$ and developing bacteremia $>10^{4} \mathrm{CFU} /$ $\mathrm{ml}$ of blood were found to have positive CSF vultures ( $P$ $<0.05$ compared to $018+\mathrm{K} 1+$ or $018-\mathrm{K} 1+$ strain ). As shown in studies with newborn rats, $E$. coli isolates obtained from adult animals infected with $018+\mathrm{K} 1-$ or $018-\mathrm{K} 1+$ mutants were also tested and no reversion to the status of their parent strain was found.

Copy number of Tn 10. One critical question for strain 2513 was that there might be multiple Tn 10 insertions affecting other virulence factors and thereby allowing strain 2513 to enter the CNS in the presence of a high degree of bacteremia. The presence of $\operatorname{Tn} 10$ was detected in E. coli strain 2513 $(018-\mathrm{K} 1+:: \mathrm{Tn} 10)$ by PCR amplification of the Tn $10 \mathrm{Tc}^{\mathrm{R}}$ gene. A 1.6-kb DNA fragment was amplified from the Tn 10 mutagenized E. coli strain $2513(018-\mathrm{K} 1+:: \mathrm{Tn} 10)$ and from $S$. typhimurium strain $\times 3604$ (cya::Tn 10 ) but not from $E$. coli parent strain C5 $(018+\mathrm{K} 1+)$. Because $\mathrm{Tc}^{\mathrm{R}}$ gene primers amplify an internal 1.6-kb fragment within Tn 10, one cannot determine if $E$. coli strain $2513(018-\mathrm{K} 1+:: \mathrm{Tn} 10)$ contained one or more copies of Tn 10. To address this question, genomic DNA digested with restriction endonucleases EcoR1, EcoR1/ Pst 1, Bam H1, Hind III, and Bgl 2 (lanes 2-6; Fig. 5) was probed with $\mathrm{Tc}^{\mathrm{R}}$ DNA amplified from $S$. typhimurium strain $\times 3604$ (cya::Tn 10). The $\mathrm{Tc}^{\mathrm{R}}$ probe detected the predicted internal 2.6-kb Bgl 2 DNA fragment (lane 6; Fig. 5) and 4.9-kb Hind III DNA fragment (lane 5; Fig. 5). Tn 10 contained a single Bam $\mathrm{H} 1$ site located to the left of $\mathrm{Tc}$ resistance gene and a single EcoR1 site spanned by the $\mathrm{Tc}^{\mathrm{R}}$ probe (Fig. 5 ). Only two EcoR1 (lane 2, 15.1 and $5.6 \mathrm{~kb}$; Fig. 5) and one Bam H1 (lane 4, $8.9 \mathrm{~kb}$; Fig. 5) fragments hybridized to the $T \mathrm{c}^{\mathrm{R}}$ probe. A Pst 1 site was mapped to the $15.1-\mathrm{kb}$ EcoR 1 fragment (lane 3, $7.8 \mathrm{~kb}$; Fig. 5) by digesting $E$. coli 2513 (018-K1+::Tn 10) with both EcoR 1 and Pst 1 . These results showed that $E$. coli strain 2513 (018-K1+::Tn 10) contained a single Tn 10 insertion. E. coli parent strain C5 $(018+K 1+)$ did not hybridize with the $\mathrm{Tc}^{\mathbf{R}}$ probe.

\section{Discussion}

Inadequate knowledge of the pathogenesis and pathophysiology has contributed to the significant mortality and morbidity associated with neonatal bacterial meningitis. For example, it is not clear why $E$. coli strains possessing the $\mathrm{Kl}$ capsule are predominant among isolates from neonatal $E$. coli meningitis and also why most of these $\mathrm{K} 1$ isolates are clonally associated with a limited number of 0 types.

We and others have shown the importance of both $\mathrm{K}$ and 0 surface determinants in conferring serum resistance $(21,22$, $25)$, which is the essence of bacteremia. In contrast, for the development of meningitis, a sequelae of $E$. coli bacteremia, the K1 capsule, but not the LPS phenotype, appears to be the critical determinant. This is true not only with $\mathrm{K} 1+E$. coli, where strains with rough LPS can induce meningitis (11), but also with group B meningococcus, where the LPS is typically of a rough phenotype (26). Thus, the 0 serogroups that are associated with the $\mathrm{K} 1$ encapsulated $E$. coli strains causing meningitis in neonates (e.g., 018, 07, 01, 016) may be relevant to the pathogenesis of bacteremic stage of disease, but not to the meningitis. $\mathrm{K} 1$ strains possessing certain 0 types may resist clearance from the bloodstream, thus allowing replication to a level that is required for meningeal invasion. Several studies in humans and experimental animals suggest a relationship between the magnitude of bacteremia and the development of meningitis (27-31). Dietzman et al. (30) reported a higher incidence of $E$. coli meningitis in neonates who had bacterial counts in blood $>10^{3} \mathrm{CFU} / \mathrm{ml}(6 / 11$ or $60 \%)$ compared to those bacterial counts in blood $<10^{3} \mathrm{CFU} / \mathrm{ml}(1 / 19$ or $5 \%)$. As shown in the present study, a high degree of bacteremia was a primary determinant for meningeal invasion by $\mathrm{K} 1 E$. coli strains regardless of status of LPS phenotype (smooth or rough). These findings suggest that one of the reasons for the close association 

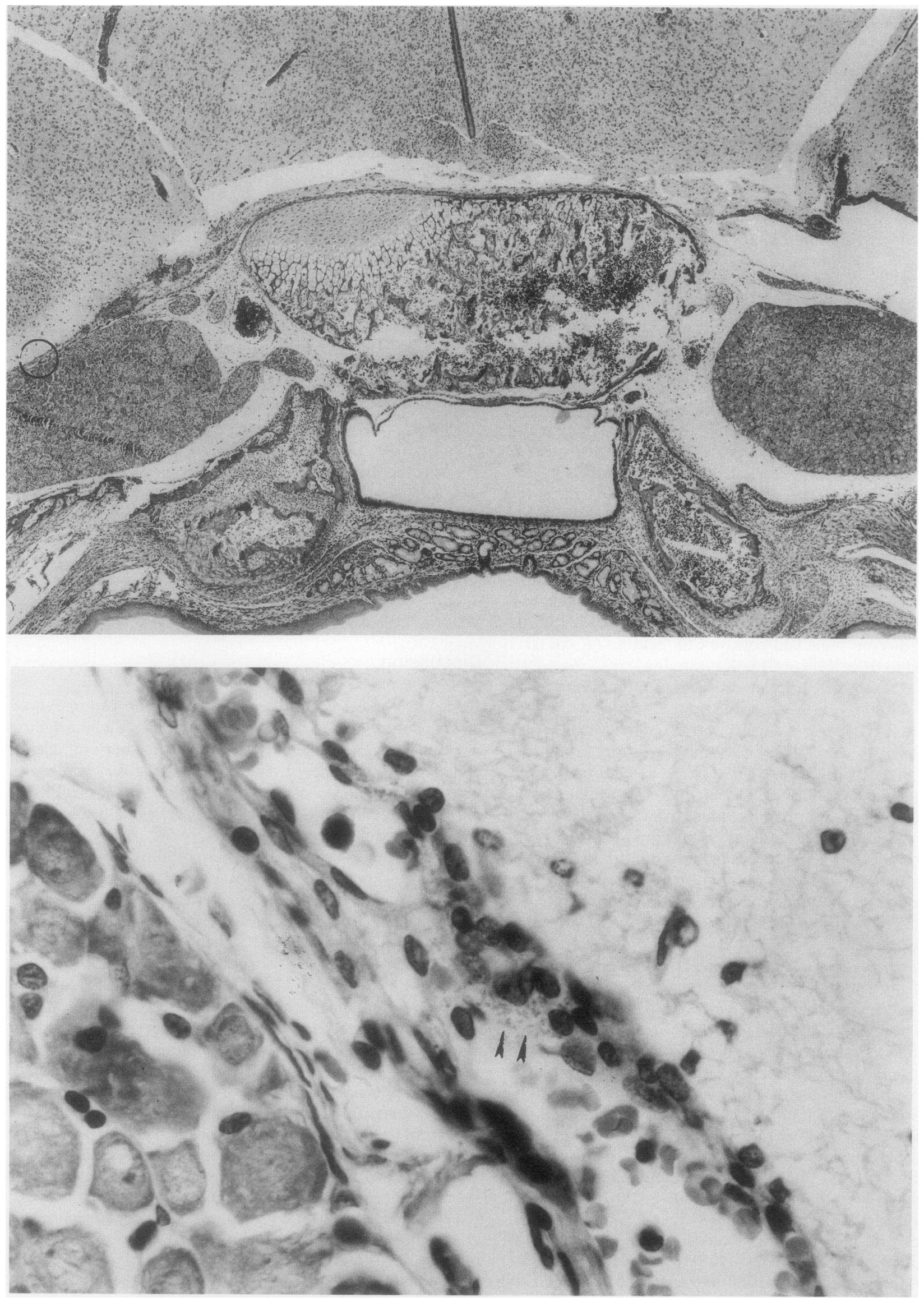

Figure 1. (Top) Coronal section of the base of the brain at frontal level with original magnification of 30 from a 5-d-old rat infected with $E$. coli strain C5 $(018+\mathrm{K} 1+)$ and was found to have meningitis (defined as positive CSF culture). (Bottom) 630 magnification of the circled portion of upper panel shows the presence of bacteria (arrows) without any evidence of inflammatory cells in the subarachnoid space. 

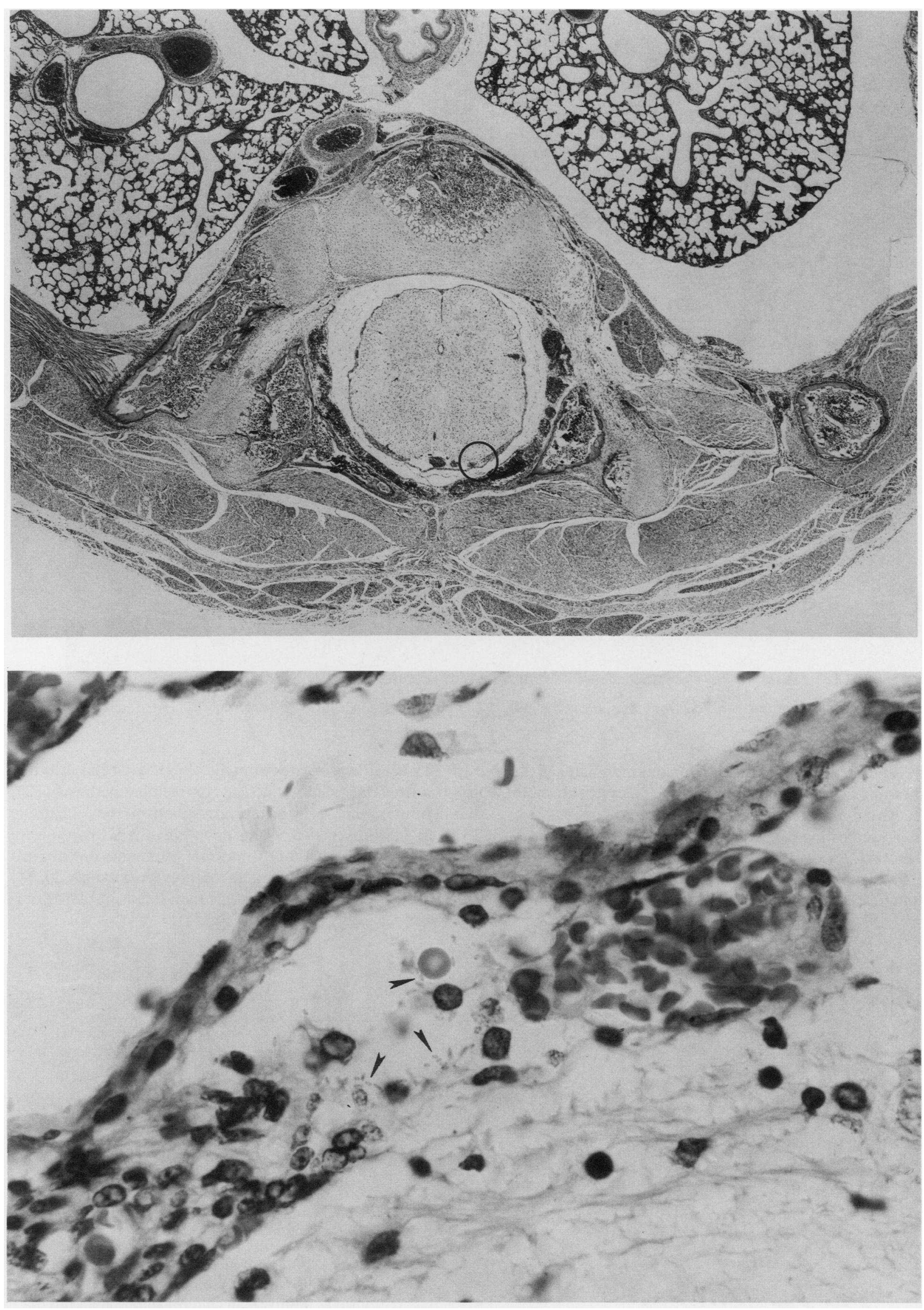

Figure 2. (Top) Coronal section of spinal cord at thoracic level with original magnification of 16 from a 5-d-old rat infected with a rough mutant of strain C5 $(018-\mathrm{K} 1+)$ and also was found to have meningitis (defined as positive CSF culture). (Bottom) 630 magnification of the circled portion of upper panel shows the presence of bacteria (arrows) without inflammatory cells in the subarachnoid space. 


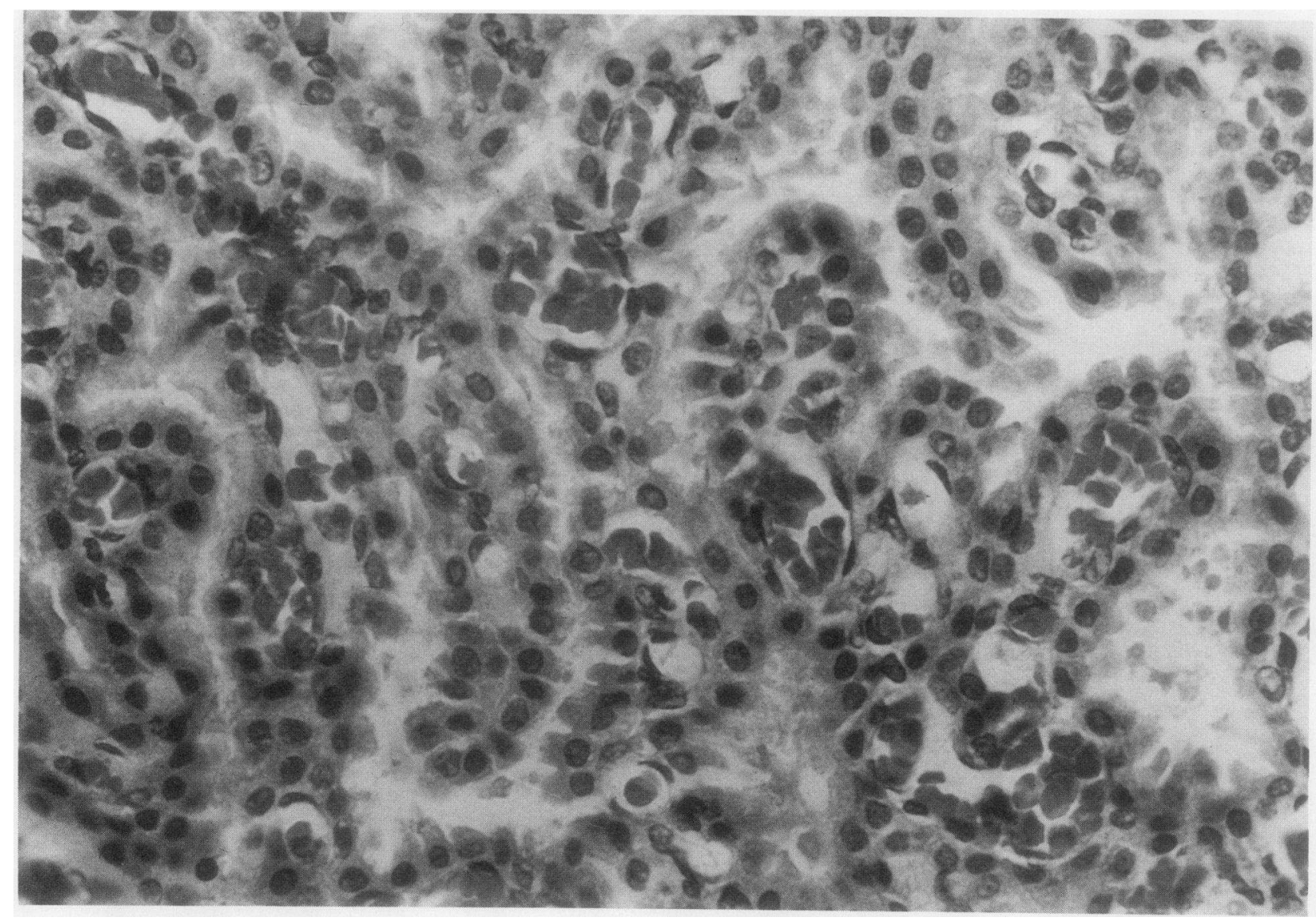

Figure 3. Choroid plexus of lateral ventricle from the same rat as in fig. 1 (430 magnification) shows no bacteria.

of certain $\mathrm{K} 1 E$. coli serotypes with neonatal meningitis is the ability to escape from host defenses and to achieve a threshold level of bacteremia necessary for meningeal invasion.

Previous studies to correlate the association of certain microbial factors of $E$. coli with the ability to replicate in vivo are not clear. For example, K1 capsular polysaccharides have been shown to increase the serum resistance of rough $E$. coli strains
(18-22). K1 E. coli isolates from the blood have been shown to be opsonized only via the classical complement pathway (32), but in humans there is little natural antibody to the $\mathrm{K} 1$ capsule (33). In addition, E. coli strains possessing the $\mathrm{K} 1$ capsule are considerably more resistant to normal human serum in vitro $(20,34)$ and as shown here and in our previous studies $(20,34)$ were more virulent in newborn rats than unencapsulated mu-

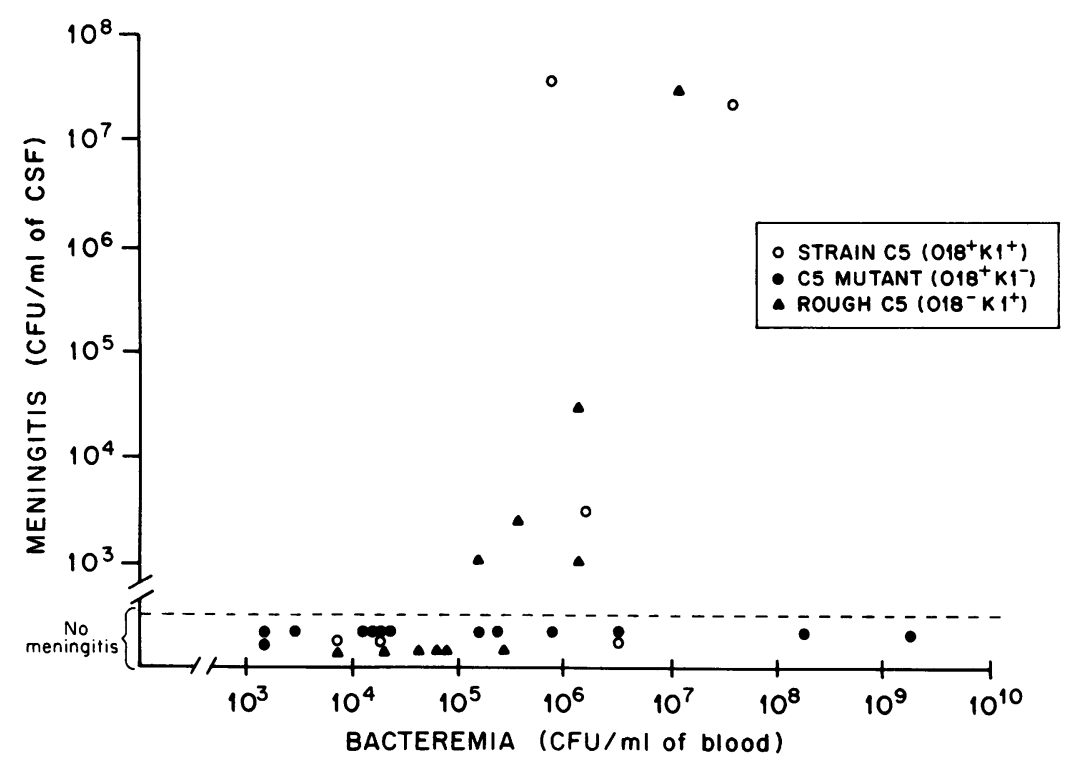

Figure 4. Relationship between the magnitude of bacteremia and the development of meningitis (defined as positive CSF culture) among adult rats developing varying degrees of bacteremia caused by $E$. coli strain C5 $(018+\mathrm{K} 1+)$, its unencapsulated $(018+\mathrm{K} 1-)$ or rough mutants $(018-\mathrm{K} 1+)$. 


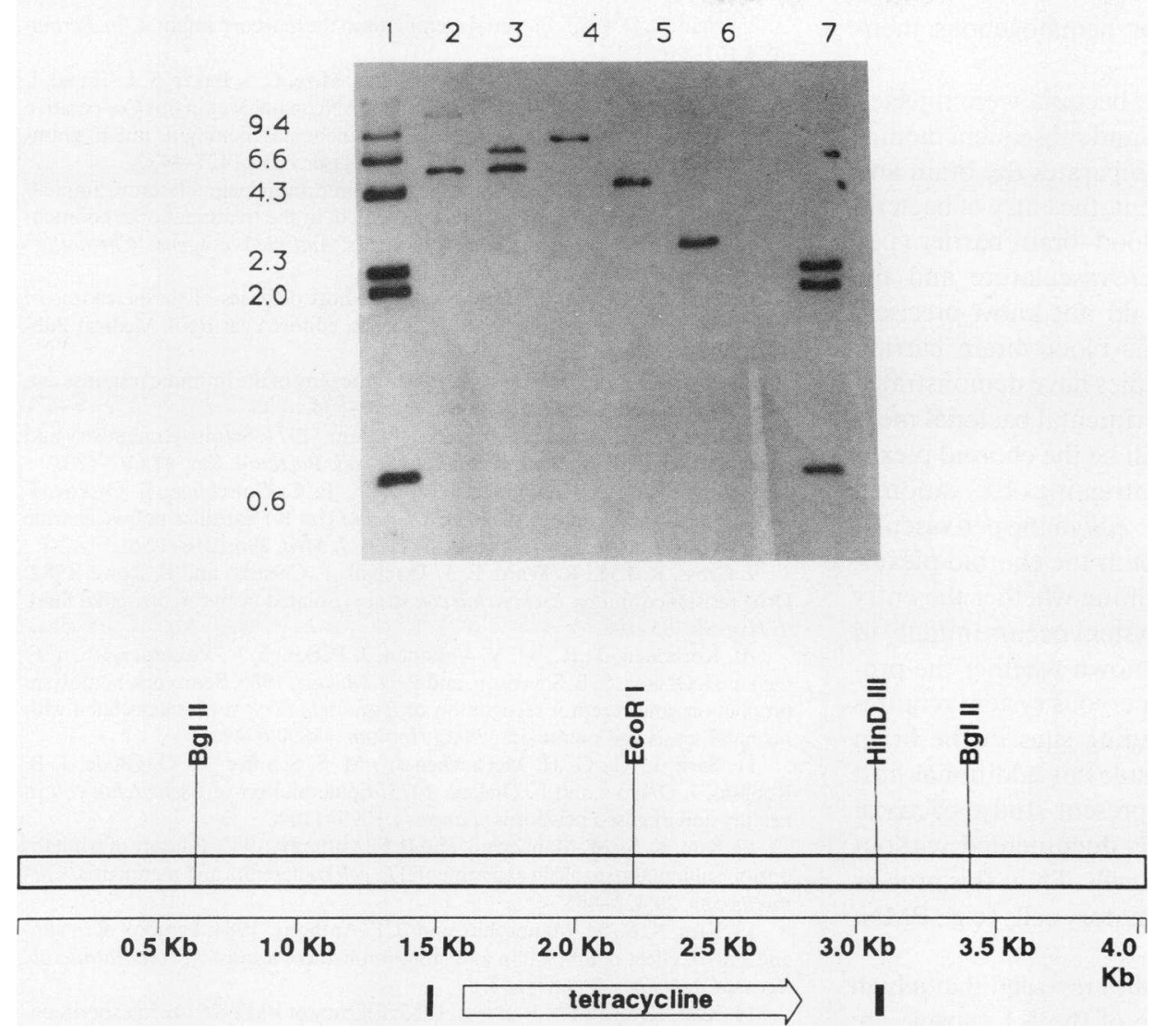

Figure 5. Hybridization of genomic DNA isolated from $E$. coli strain $2513(018-\mathrm{K} 1+:: \mathrm{Tn} 10)$ with $\mathrm{Tc}^{\mathrm{R}}$ probe. Genomic DNA was digested with restriction endonucleases EcoR1, EcoR1/Pst1, BamH1, Hind III, and Bgl 2, separated by agarose gel electrophoresis, and blotted to nylon membranes. Fluorescein-11 dUTP (Amersham International, Bucks, UK) labeled $\mathrm{Tc}^{\mathrm{R}}$ probe DNA hybridized to the nylon membrane was detected with phosphatase-labeled anti-fluorescein antibody and luminol substrate (Amersham International). Lanes 1 and 7, Hind III digested Lambda molecular weight standards. Lane 2, EcoR 1; lane 3, EcoR1 Pst1; lane 4, BamH1; lane 5, Hind III, and lane 6, Bgl 2. Restriction endonuclease map of tetracycline resistance gene of $\operatorname{Tn} 10$ base on DNA sequence (23). The black boxes represent the PCR primers used to amplify the $\mathrm{Tc}^{\mathrm{R}}$ probe DNA. tants. This suggests that for the demonstration of serum resistance and in vivo virulence the $\mathrm{K} 1$ capsule is required. In contrast, other investigators suggest that other microbial surface factors may also affect virulence. Smooth LPS antigen (rather than $\mathrm{K}$ antigen) has been shown to be a virulence factor for serum resistance of $E$. coli $(35,36)$. The concept that some smooth LPS types can function as virulence determinants, however, does not apply to all instances of meningitis and therefore poses a paradox. For instance, $\sim 20 \%$ of $\mathrm{K} 1 \mathrm{E}$. coli isolates from neonatal meningitis spontaneously agglutinate in saline, suggesting rough LPS phenotype (11). In the present study, we obtained two different rough mutants. Although these rough mutants were considerably less virulent compared to the parent smooth LPS strain (i.e., $\sim 10^{5}$-fold greater $\mathrm{LD}_{50}$ 's compared to the parent strain ), they were able to induce meningitis in the presence of a high degree of bacteremia provided the $\mathrm{K} 1$ capsule was also present (Table I). These findings suggest that a smooth LPS phenotype is not required for meningeal invasion by K1-encapsulated $E$. coli strains. Thus, one of the reasons for the close association of certain 0 serotypes or rough LPS of K1 E. coli with neonatal meningitis may be that these LPS phenotypes of $E$. coli have evolved with the K1 capsule for protection from serum bacteriolysis. This concept is based on the previous demonstration that the $\mathrm{K} 1$ capsule is associated with a relatively limited number of 0 serotypes, particularly those LPS phenotypes that are unable to protect the bacteria from killing by normal human sera in the absence of capsule $(21,22,37)$.

One intriguing observation was that the induction of a high degree of bacteremia alone was not sufficient for the development of meningitis by $E$. coli. This was demonstrated by our inability to induce meningitis in newborn as well as in adult animals infected with the unencapsulated $(\mathrm{K} 1-)$ mutant despite the production of a high degree of bacteremia (up to $10^{8}$ to $10^{9} \mathrm{CFU} / \mathrm{ml}$ of blood). These findings indicate that the presence of the $\mathrm{K} 1$ capsule is a critical element that is required in addition to the achievement of a high degree of bacteremia for the development of $E$. coli meningitis. The $\mathrm{K} 1$ capsule, which is a homopolymer of sialic acid, is immunochemically identical to group B meningococcal capsular polysaccharide (38). These bacteria, which are of diverse evolutionary background and have little genetic homology, share a common biochemical capsule and both lead to an infection of the same anatomic site, the meninges. This suggests some specific interaction of the capsule with host brain tissue, which may be responsible for the entry of $\mathrm{K} 1$-encapsulated $E$. coli into the meninges. The two rough mutants used in these studies, strains XYL and 2513, were derived by different methods (nitrosoguanidine and transposon mutagenesis). In that a great many genetic loci are involved in the synthesis of LPS (39), it is likely that these two different methods of mutagenesis altered different sites of LPS synthesis and consequently, strains XYL and 2513 were probably two different mutants. While these two mutants may differ in some characteristics not examined by us, nevertheless, both mutants did exhibit a rough LPS phenotype but retained the $\mathrm{K} 1$ capsule, were identical by multilocus enzyme electrophoresis and behaved similarly in animal studies. In addition, Southern blot analysis of strain 2513 revealed a single Tn 10 insertion, suggesting that strain 2513 stems from a single lesion in the genesis of LPS without affecting other virulence factors. The data obtained with strain 2513 (Table I) further support the idea that the K1 capsule, not the LPS pheno- 
type, is an important determinant for hematogenous meningitis.

In our experimental animal model, bacteria were injected subcutaneously, resulting in bacteremia and subsequent meningitis. Because the blood-brain barrier separates the brain and CSF from the intravascular compartment, the entry of bacteria should have occurred at the sites of blood-brain barrier (i.e., the choroid plexus, the cerebral microvasculature and the arachnoid membrane). We presently do not know precisely how $\mathrm{K} 1$ encapsulated $E$. coli cross the blood-brain barrier. Inasmuch as previous morphologic studies have demonstrated an intact arachnoid membrane in experimental bacterial meningitis $(40,41)$, the most likely sites will be the choroid plexus and/or the cerebral vasculature. One intriguing observation in this respect was the demonstration of $E$. coli in the perivascular area of the subarachnoid space, but not in the choroid plexus. Additional studies are needed to determine whether the entry of $\mathrm{K} 1 E$. coli into the central nervous system occurs initially in the cerebral vasculature. It is also unknown whether the process of bacterial entry into the central nervous system requires specific structure(s) (e.g., specific binding sites in the brain which have an affinity for the $\mathrm{K} 1$ capsule) or additional host factor(s). However, as shown in the present study, bacterial entry into the subarachnoid space was documented without concomitant presence of inflammatory cells. Thus, this process does not appear to require host inflammatory cells (e.g., PMN, macrophages).

In summary, our experimental studies revealed that a high degree of bacteremia and the presence of the $\mathrm{K} 1$ capsule are important determinants in the development of $E$. coli meningitis. Based on these findings, it appears that the prevention of bacterial multiplication in the blood that is required for bacterial entry into the central nervous system would be one potential approach to the prevention of $E$. coli meningitis. This approach may be feasible because administration of functionally active antibodies alone or in combination with antibiotics have been shown to decrease the level of bacteremia (42-45). In addition, the number of 0 antigens common in neonatal $E$. coli meningitis are limited (11) and techniques are available for preparing nontoxic 0 polysaccharide conjugate vaccines (46) as well as hyperimmune globulin containing opsonic antibodies against several 0 antigens. By using hyperimmune globulin, a large quantity of functional anti-0 LPS antibody can be administered in a comparatively small volume, thus possibly circumventing at least some of the adverse reactions noted upon giving large volumes of nonhyperimmune globulin preparations (47). Further investigations on the role of immunotherapy (e.g., hyperimmune globulin) for controlling neonatal $E$. coli sepsis and meningitis are therefore warranted.

\section{Acknowledgments}

This study was supported in part by R01-NS-26310 from the National Institute of Neurological and Communicative Disorders and Stroke. We thank Jane Kang and Carol Wass for their technical assistance, Dr. Wilson at $E$. coli Reference Center, Pennsylvania State University, for performing the multilocus enzyme electrophoresis, and Cynthia Hunter for typing this manuscript.

\section{References}

1. Siegel, J. D., and G. H. McCracken, Jr. 1981. Sepsis neonatorum. N. Engl. J. Med. 304:642-467.
2. Feigin, R. D. 1977. Bacterial meningitis in the newborn infant. Clin. Perinatol. 4:103-116.

3. McCracken, G. H., Jr., N. Threlkeld, S. Mize, C. J. Baker, S. L. Kapal, I. Faingezicht, W. E. Feldman, U. Schad, and the Neonatal Meningitis Cooperative Study Group. 1984. Moxalactam therapy for neonatal meningitis due to gramnegative enteric bacilli. JAMA (J. Am. Med. Assoc.) 252:1427-1432.

4. Kim, K. S. 1985. Comparison of cefotaxime, imipenem-cilastatin, ampicillin-gentamicin, and ampicillin-chloramphenicol in the treatment of experimental Escherichia coli bacteremia and meningitis. Antimicrob. Agents. Chemother. 28:433-436.

5. Miller, M. E. 1978. Current topics in host defenses of the newborn. In Advances in Pediatrics, Vol. 25. L. A. Barnes, editor. Year Book Medical Publishers, Inc., Chicago. 59-95.

6. Pabst, H. F., and H. W. Kreth. 1980. Ontogeny of the immune response as a basis of childhood disease. J. Pediatr. 97:519-534.

7. Orskov, I., F. Orskov, B. Jann, and K. Jann. 1977. Serology, chemistry and genetics of 0 and $\mathrm{K}$ antigens of Escherichia coli. Bacteriol. Rev. 41:667-683.

8. Robbins, J. B., G. H. McCracken, Jr., E. C. Gotschlich, F. Orskov, I. Orskov, and L. A. Hanson. 1974. Escherichia coli K1 capsular polysaccharide associated with neonatal meningitis. N. Engl. J. Med. 290:1216-1220.

9. Gross, R. J., L. R. Ward, E. J. Threlfall, T. Cheasty, and B. Rowe. 1982. Drug resistance among Escherichia coli strains isolated from cerebrospinal fluid. J. Hyg. 90:195-198.

10. Korhonen, T. K., M. V. Valtonen, J. Parkinen, V. Vaisamen-Rhen, F. Orskov, I. Orskov, S. B. Sevenson, and P. H. Makela. 1985. Serotypes, hemolysin production, and receptor recognition of Escherichia coli strains associated with neonatal sepsis and meningitis. Infect. Immun. 488:486-491.

11. Sarff, L. C., G. H. McCracken Jr., M. S. Schiffer, M. O. Glode, J. B. Robbins, I. Orskov, and F. Orskov. 1975. Epidemiology of Escherichia coli in healthy and diseased newborns. Lancet. 1:1099-1 104.

12. Kim, K. S., M. Manocchio, and B. F. Anthony. 1983. Efficacy of trimethoprim/sulfamethoxazole in experimental $E$. coli bacteremia and meningitis. Chemotherapy. 29:428-435.

13. Kim, K. S., M. Manocchio, and B. F. Anthony. 1984. Paradox of in vitro and in vivo effect of ampicillin and chloramphenicol against E. coli. Antmicrob. Agents Chemother. 26:689-693.

14. Kim, K. S., and A. B. Bayer. 1985. Efficacy of BMY-28142 in experimental bacteremia and meningitis due to Escherichia coli and group B streptococci. Antimicrob. Agents Chemother. 28:51-54.

15. Kim, K. S. 1985. Efficacy of cefmenoxime in experimental Escherichia coli bacteremia and meningitis. Antimicrob. Agents Chemother. 28:389-393.

16. Kim, K. S., M. Manocchio, and A. S. Bayer. 1984. Efficacy of cefotaxime and moxalactam for $E$. coli bacteremia and meningitis in newborn rats. Chemotherapy. 30:262-269.

17. Kim, K. S. 1985. Comparison of gentamicin and kanamycin alone and in combination with ampicillin in experimental $E$. coli bacteremia and meningitis. Pediatr. Res. 19:1152-1155.

18. Gemski, P., A. S. Cross, and J. C. Sadoff. 1980. K1 antigen associated resistance to the bactericidal activity of serum. FEMS (Fed. Eur. Microbiol. Soc.) Lett. 9:192-197.

19. Opal, S., A. Cross, and P. Gemski. 1982. K antigen and serum sensitivity of rough Escherichia coli. Infect. Immun. 37:956-960.

20. Cross, A. S., K. S. Kim, D. C. Wright, J. C. Sadoff, and P. Gemski. 1986 Role of lipopolysaccharide and capsule in the serum resistance of bacteremic strains of E. coli. J. Infect. Dis. 154:497-503.

21. Cross, A. S., P. Gemski, J. C. Sadoff, F. Orskov, and I. Orskov. 1984. The importance of the $\mathrm{K} 1$ capsule in invasive infections caused by Escherichia coli. J. Infect. Dis. 149:194-193.

22. Cross, A., J. Sadof, P. Gemski, L. Asher, and K. S. Kim. 1988. The relative role of lipopolysaccharide and capsule in the virulence of $E$. coli. In Bacteria, Complement and Phagocytic Cell. Proceedings of NATO Workshop. F. Cabello and C. Pruzzo, editors. NATO ASI Services, Vol. H24, Springer-Verlag, Berlin. 319-133.

23. Bertrand, K. P., K. Postle, L. V. Wray, Jr., and W. S. Reznikoff. 1983. Overlapping divergent promoters control expression of Tn 10 tetracycline resistance. Gene. 23:149-156.

24. Chumley, F. G., R. Menzel, and T. R. Roth. 1979. Hfr formation directed Tn 10. Genetics 91:639-655.

25. Pluschke, G., J. Mayden, M. Achtman and R. P. Levine. 1983. Role of the capsule and the 0 antigen in resistance of 018:K1 Escherichia coli to complementmediated killing. Infect. Immun. 42:907-913.

26. Schneider, H., T. L. Hale, W. D. Zollinger, R. C. Seid, Jr., C. A. Hammack, and J. McLeod. 1984. Heterogeneity of molecular size and antigenic expression within lipopolysaccharides of individuals strains of Neisseria gonorrhea and Neisseria meningitidis. Infect Immun. 45:544-549.

27. Sullivan, T. D., L. J. LaScolea, and E. Neter. 1982. Relationship between the magnitude of bacteremia in children and the clinical disease. Pediatrics. 69:699-702.

28. LaScolea, L. J., and D. Dryja. 1984. Quantitation of bacteria in cerebrospi- 
nal fluid and blood of children with meningitis and its diagnostic significance. $J$. Clin. Microbiol. 19:187-190.

29. Bell, L. M., G. Alpert, J. M. Campos, and S. A. Plotkin. 1985. Routine quantitative blood cultures in children with Haemophilus influenzae or Streptococcus pneumoniae bacteremia. Pediatrics. 76:901-904.

30. Dietzman, D. E., G. W. Fischer, and F. D. Schoenknecht. 1974. Neonata Escherichia coli septicemia-bacterial counts in blood. J. Pediatr. 85:128-130.

31. Petersdorf, R. G., D. R. Swarner, and M. Garcia. 1962. Studies on the pathogenesis of meningitis. II. Development of meningitis during pneumococcal bacteremia. J. Clin. Invest. 41:320-327.

32. Stevens, P., S. N.-Y. Huang, W. D. Welch, and L. S. Young. 1980. Restricted complement activation by Escherichia coli with the K1 capsular serotype: a possible role in pathogenicity. J. Immunol. 121:2174-2180.

33. Cross, A. S., W. Zollinger, R. Mandrell, P. Gemski, and J. Sadoff. 1983. Evaluation of immunotherapeutic approaches for the potential treatment of infections caused by K1-positive Escherichia coli. J. Infect. Dis. 147:68-76.

34. Kim, K. S., J. H. Kang, and A. S. Cross. 1986. The role of capsular antigens in serum resistance and in vivo virulence of Escherichia coli. FEMS (Fed. Eur. Microbiol. Soc.) Lett. 35:275-278.

35. Medearis, D. N., Jr., B. M. Camitta, and E. C. Heath. 1968. Cell wall composition and virulence Escherichia coli. J. Exp. Med. 128:399-414.

36. McCabe, W. R., B. Kaijser, S. Olling, M. Uwaydah, and L. A. Hanson. 1978. Escherichia coli in bacteremia: $\mathrm{K}$ and 0 antigens and serum sensitivity of strains from adults and neonates. J. Infect. Dis. 138:33-41.

37. Vermeulen, C., A. Cross, W. R. Bryne, and W. Zollinger. 1988. Quantitative relationship between capsular content and killing of $\mathrm{K} 1$-encapsulated Escherichia coli. Infect. Immun. 56:2723-2730.

38. Kasper, D. L., L. J. Winkelhake, W. D. Zollinger, B. L. Brandt, and M. S.
Artenstein. 1973. Immunochemical similarity between polysaccharide antigens of Escherichia coli 07:K1(L):NM and group B Neisseria meningitidis. J. Im munol. 110:262-268.

39. Osborn, M. J. 1969. Structure and biosynthesis of the bacterial cell wall Annu. Rev. Biochem. 38:501-538.

40. Waggener, J. D. 1974. The pathophysiology of bacterial meningitis and cerebral abscesses: an anatomical interpretation. Adv. Neurol. 6:1-17.

41. Nelson, E., K. Blinzinger, and J. Hager. 1962. An electron microscope study of bacterial meningitis. I. Experimental alterations in the leptomeninges and subarachonis space. Arch. Neurol. 6:398-405.

42. Kim, K. S., J. H. Kang, A. S. Cross, B. Kaufman, W. Zollinger, and J. Sadoff. 1988. Functional activities of monoclonal antibodies to the 0 side chain of Escherichia coli lipopolysaccharides in vitro and in vivo. J. Infect. Dis. 157:47-53.

43. Kim, K. S., A. S. Cross, W. Zollinger, and J. Sadoff. 1985. Prevention and therapy of experimental $E$. coli infection with monoclonal antibody. Infect. Immun. 50:734-737.

44. Kim, K. S., A. Cross, and J. Sadoff. 1990. Monoclonal antibody to the 0 -side chain Escherichia coli enhances the efficacy of cefotaxime against experimental K $1 E$. coli infection caused by a homologous 0 type. Serodiagn. Immunother. Infect. Dis. 4:95-99.

45. Kim, K. S. 1987. Efficacy of human immunoglobulin and penicillin $\mathrm{G}$ in treatment of experimental group B streptococcal infection. Pediatr. Res. 21:289292.

46. Cryz, S. J., A. S. Cross, J. C. Sadoff, and E. Furer. 1990. Synthesis and characterization of Escherichia coli 018 0-polysaccharide conjugate vaccines. In fect. Immun. 58:373-377.

47. Kim, K. S. 1989. High dose intravenous immune globulin impairs antibacterial activity of antibiotics. J. Allergy Clin. Immunol. 84:579-588. 